\title{
An adenosine A1R-A2aR imbalance regulates low glucose/hypoxia-induced microglial activation, thereby contributing to oligodendrocyte damage through NF-kB and CREB phosphorylation
}

\author{
WEN HUANG $^{1}$, SHUNJIE BAI ${ }^{2}$, XUZHENG ZUO ${ }^{1}$, WEIJU TANG ${ }^{1}$, PENGFEI CHEN ${ }^{2}$, \\ XIUYING CHEN ${ }^{1}$, GONG WANG $^{1}$, HAOXIANG WANG ${ }^{1}$ and PENG XIE ${ }^{2}$ \\ ${ }^{1}$ Department of Neurology, Xinqiao Hospital, Third Military Medical University, Chongqing 400038; \\ ${ }^{2}$ Department of Neurology, The First Affiliated Hospital of Chongqing Medical University, Chongqing 400016, P.R. China
}

Received September 30, 2016; Accepted January 9, 2018

DOI: $10.3892 /$ ijmm.2018.3546

\begin{abstract}
Microglial activation-mediated inflammatory damage to oligodendrocytes is a key step in the etiology of ischemic white matter lesions. The adenosine A1 receptor $(\mathrm{A} 1 \mathrm{R})$ and adenosine $\mathrm{A} 2 \mathrm{a}$ receptor $(\mathrm{A} 2 \mathrm{aR})$ have been reported to regulate the activation of microglia, however, the underlying mechanisms remain elusive. Thus, the present study used a microglia/oligodendrocyte co-culture model exposed to low glucose/hypoxia, and treated with agonists/antagonists of A1R and $\mathrm{A} 2 \mathrm{aR}$ to investigate the role of $\mathrm{A} 1 \mathrm{R}$ and $\mathrm{A} 2 \mathrm{aR}$. Changes in $\mathrm{A} 1 \mathrm{R}$ and $\mathrm{A} 2 \mathrm{aR}$ expression and inflammatory cytokine secretion by the microglia, and oligodendrocyte damage, after exposure were examined. Low glucose/hypoxia induced a higher elevation of A1R than A2aR. In addition, activation of A1R inhibited A2aR protein expression and vice versa. The A1R antagonist DPCPX (100 $\mathrm{nM})$ and A2aR agonist CGS $21680(100 \mathrm{nM})$ inhibited microglial activation, reduced the production of inflammatory cytokines and attenuated oligodendrocyte damage, along with elevating the levels of phosphorylated nuclear factor (NF)- $\mathrm{\kappa B}$ and cyclic adenosine monophosphate response element binding protein (CREB). These data indicate that an A1R-A2aR imbalance is able to modulate low glucose-induced microglial activation and the cellular immune response through altering NF- $\kappa B$ and CREB
\end{abstract}

Correspondence to: Professor Wen Huang, Department of Neurology, Xinqiao Hospital, Third Military Medical University, 29 Gaotanyan Street, Chongqing 400038, P.R. China

E-mail: bosshuangwen@126.com

Professor Peng Xie, Department of Neurology, The First Affiliated Hospital of Chongqing Medical University, 1 Youyi Road, Chongqing 400016, P.R. China

E-mail: xiepeng973@126.com

Key words: adenosine A1 receptor, adenosine A2a receptor, microglial activation, oligodendrocyte, inflammatory cytokines phosphorylation. This suggests that rebalancing A1R-A2aR is a promising approach for treating white matter injury.

\section{Introduction}

Oligodendrocyte damage-induced demyelination is a typical pathological event in white matter impairment in numerous neurological disorders, including stroke, Alzheimer's disease, intracranial tumors, cerebral hemorrhage and chronic cerebral hypoperfusion (1). Oligodendrocytes, as the primary component of periventricular white matter and the only myelin-producing cells in the central nervous system (CNS), are fragile and vulnerable to ischemic white matter lesions (WMLs) (2). Inflammatory cytokines derived from activated microglia and astrocytes are the main factors responsible for oligodendrocyte injury (3).

Microglia are the predominant resident immune cell in the human brain and white matter (4). Microglia becomes activated under oxygen and glucose deprivation (OGD) or low glucose/hypoxia. Once activated, the morphology and secretory phenotype of the microglia changes; protrusion retraction, polarization and an increase in the soma area occurs (5). A recent study reported that OGD activated microglia, which then had neurotoxic effects on oligodendrocyte progenitor cells by inducing the rapid release of proinflammatory molecules and free radicals (6). Due to sharing analogous pathological mechanisms (7), it may be speculated that microglia will exhibit similar effects under low glucose/hypoxia conditions. Therefore, selective modulation of the activation of microglia may be a strategy for the treatment of white matter injury, such as WMLs.

There is an urgent need for treatments for microglia-induced neuroinflammation of the ischemic brain. Adenosine has been highlighted as a crucial regulatory autocrine and paracrine factor, which is required for microglial-mediated inflammatory activity (8). The extracellular ectonucleotidases cluster of differentiation (CD)39 and CD73 metabolize adenosine triphosphate (ATP) and adenosine diphosphate to adenosine monophosphate (AMP), and then metabolize AMP into 
adenosine. Subsequently, adenosine triggers an efflux of $\mathrm{K}^{+}$from the cell, followed by a $\mathrm{Ca}^{2+}$ influx and activation of phosphatidylcholine-specific phospholipase $\mathrm{C}$ and calcium-independent phospholipase A2, which induces an unconventional release of GAPDH and inflammatory cytokines from the microglia (9). However, the role of adenosine receptors (ARs) in the modulation of the secretion of inflammatory cytokines from the microglia during hypoxia is not well understood.

Adenosine is a ubiquitous nucleoside that has an influence on the immune properties of microglia through interactions with four AR subtypes; A1, A2a, A2b and A3 (10). The adenosine $\mathrm{A} 1$ receptor (A1R) and adenosine $\mathrm{A} 2 \mathrm{a}$ receptor (A2aR) have been reported to form complicated tetrameric heteromers in astrocytes and neurons, suggesting a putative regulatory interaction with $\mathrm{A} 1 \mathrm{R}$ and $\mathrm{A} 2 \mathrm{aR}$ (11). A1R and $\mathrm{A} 2 \mathrm{aR}$ have antagonistic effects on gliosis and the release of glutamate because of different couplings with the guanine nucleotide-binding $(\mathrm{G})$ proteins $\mathrm{G}_{\mathrm{i}}$ and $\mathrm{G}_{\mathrm{s}}$, and their elicitation of the release of $\mathrm{Ca}^{2+}$ from intracellular stores (12). Furthermore, activation of $\mathrm{A} 2 \mathrm{aR}$ reduces the affinity of A1R to agonists during the formation of A1R-A2aR heteromers in mammalian cells, providing a switch mechanism by which low $(0.3 \mu \mathrm{M})$ and high $(3-10 \mu \mathrm{M})$ concentrations of adenosine can inhibit and stimulate glutamatergic neurotransmission (13). Little is known about whether an imbalance of A1R to $\mathrm{A} 2 \mathrm{aR}$ contributes to the immune cascade in microglia. Our group previously demonstrated that ablation of the A2aR gene promotes microglial activation and deteriorates chronic cerebral hypoperfusion-induced WMLs (14). Given that chronic cerebral ischemia can induce a downregulation of adenosine A1R during white matter damage, the functional antagonistic interactions between A1R and A2aR that modulate the release of inflammatory cytokines from the microglia should be further investigated. In the present study, a co-culture model of microglia/oligodendrocytes undergoing low glucose/hypoxia exposure to mimic chronic cerebral hypoperfusion was utilized to determine whether an A1R-A2aR imbalance regulates the activation of microglia.

Mechanically, activation of microglia is linked to the response of transcription factors, including cyclic adenosine monophosphate (cAMP) response element binding protein (CREB) and nuclear factor (NF)- $\mathrm{B}(15)$. A1R and A2aR affect the level of cAMP through $\mathrm{G}_{\mathrm{i}}$ and $\mathrm{G}_{\mathrm{s}}$ proteins, activating cAMP-dependent protein kinase $\mathrm{A}$ (PKA), and promoting the phosphorylation of $\mathrm{CREB}$ and $\mathrm{NF}-\kappa \mathrm{B}$, thereby regulating microglial activation and the production of inflammatory cytokines $(16,17)$. Nevertheless, a better understanding of the distinct role of $\mathrm{A} 1 \mathrm{R}$ and $\mathrm{A} 2 \mathrm{aR}$ in $\mathrm{CREB}$ and $\mathrm{NF}-\kappa \mathrm{B}$ phosphorylation is required. The present study aimed to investigate whether an imbalance of A1R-A2aR regulates low glucose/hypoxia-induced microglial activation, thereby contributing to oligodendrocyte injury through modulating the phosphorylation of NF- $\kappa \mathrm{B}$ and CREB.

\section{Materials and methods}

Experimental animals. Animals were provided by Animal Center of Third Military Medical University (Chongqing, China). A total of 8 Sprague Dawley rats (3-days-old) were used in the present study. Prior to the experiment, the mice were housed in a cage at a constant temperature $\left(22 \pm 2^{\circ} \mathrm{C}\right)$ and humidity $(60 \pm 5 \%)$ with a 12 -h light/dark cycle. The rats had free access to food and water. All animal care and experimental procedures were approved by the Institutional Animal Care and Use Committee of Third Military Medical University (approval no. SYXK-PLA-2007035). Efforts were made to minimize animal suffering and to reduce the number of animals used. All surgeries were performed under sodium pentobarbital anesthesia and mice were sacrificed by cervical dislocation under deep anesthesia.

Drugs. The following drugs were used in the present study (Table I): A1R agonist, 2-chloro-N6-cyclopentyladenosine (CPA); A1R antagonist, cyclopentyl-1,3-dipropylxanthine (DPCPX); A2AR agonist, 2-p-(carboxyethyl) phenethylamino-5'-N-ethylcarboxamideadenosine hydrochloride (CGS 21680); and A2AR antagonist, 2-(2-furanyl)-7-(2-phenylethyl)7H-pyrazolo[4,3-e] [1,2,4]triazolo[1,5-c]pyrimidin-5-amine (SCH 58261). Saline, $5 \mathrm{mM}$ dimethylsulfoxide and $10 \mathrm{mM}$ ethanol were used for the vehicle. The drugs were purchased from eBioscience (Thermo Fisher Scientific, Inc., Waltham, MA, USA).

Microglia culture. The microglial cell line BV2 (Cell Resource Center, Institute of Basic Medical Sciences, Chinese Academy of Medical Sciences/Peking Union Medical College, Beijing, China) was used. The cells were cultured in Dulbecco's modified Eagle medium (low glucose; Invitrogen; Thermo Fisher Scientific, Inc.), $5 \%$ fetal bovine serum (FBS; HyClone; GE Healthcare Life Sciences, Logan, UT, USA), 4 mM glutamine (Invitrogen; Thermo Fisher Scientific, Inc.), 100,000 U/1 penicillin $\mathrm{G}$ and $100 \mathrm{mg} / 1$ streptomycin (Mediatech, Inc., Herndon, $\mathrm{VA}, \mathrm{USA}$ ), and were maintained at $37^{\circ} \mathrm{C}$ with $5 \% \mathrm{CO}_{2}$.

Oligodendrocyte culture. Primary oligodendrocyte cultures were isolated and maintained as described by Seki et al (18). Briefly, the subventricular zone was removed from 3-day-old Sprague Dawley rats $(n=8)$ using a dissecting microscope. The tissues were mechanically dissociated into single cells on 100-mm-pore nylon mesh cell strainers (BD Biosciences, Franklin Lakes, NJ, USA) and collected in PBS. Subsequently, the cells were filtered through 40-mm-pore nylon mesh cell strainers (BD Biosciences) and centrifuged at $800 \mathrm{x}$ g for $5 \mathrm{~min}$ at $4^{\circ} \mathrm{C}$. The cell pellet was re-suspended in cold Neurobasal Medium supplemented with 2\% B27, 1\% L-glutamine, 1\% penicillin/streptomycin/amphotericin B (all Thermo Fisher Scientific, Inc.), $20 \mathrm{ng} / \mathrm{ml}$ epidermal growth factor and $10 \mathrm{ng} / \mathrm{ml}$ basic fibroblast growth factor (both Sigma-Aldrich, Merck KGaA, Darmstadt, Germany). The cell suspension was plated into poly-L-lysine coated 12 -well plates at a density of $1.5 \times 10^{5}$ cells/well. Cells were maintained at $37^{\circ} \mathrm{C}$ in an atmosphere of $5 \% \mathrm{CO}_{2}$. At day 7, triiodothyronine (T3; $30 \mu \mathrm{g} / \mathrm{ml}$ ) and thyroxine (T4; $40 \mu \mathrm{g} / \mathrm{ml}$ ) (both Sigma-Aldrich; Merck KGaA) were added to the culture media. A total of 14 days after the addition of T3 and T4, the differentiated oligodendrocytes were subjected to further experiments.

Co-culture model of microglia and oligodendrocytes. As previously described (18), BV2 microglial cells were plated on tissue culture inserts for 12-well plates (Greiner 
Table I. A1R and A2aR agonists and antagonists used and their effects.

\begin{tabular}{lcl}
\hline Drug & Dosage $(\mathrm{nM})$ & \multicolumn{1}{c}{ Effect } \\
\hline CPA & 1,000 & Activated A1R \\
DPCPX & 100 & Inhibits'A1R \\
CGS & 100 & Activates A2aR \\
SCH & 100 & Inhibits A2aR \\
\hline
\end{tabular}

$\mathrm{A} 1 \mathrm{R}$, adenosine $\mathrm{A} 1$ receptor; $\mathrm{A} 2 \mathrm{aR}$, adenosine $\mathrm{A} 2 \mathrm{a}$ receptor.

Bio-One GmbH, Frickenhausen, Germany) at a density of $5 \times 10^{5}$ cells/well. The microglial cells were incubated for $12 \mathrm{~h}$ in the presence of CPA $(1 \mu \mathrm{M})$, DPCPX $(100 \mathrm{nM})$ CGS $(100 \mathrm{nM})$ or $\mathrm{SCH}(100 \mathrm{nM})$. In triplicate, using 5- $\mu \mathrm{m}$ pore Transwell filters (Corning Incorporated, Corning, NY, USA), each BV2 culture insert was placed on the primary oligodendrocytes $\left(1.5 \times 10^{5}\right.$ cells $\left./ \mathrm{cm}^{2}\right)$ in the 12 -well plates. Both layers of cells were submerged in Neurobasal Medium with the aforementioned supplements. A total of $24 \mathrm{~h}$ after a $37^{\circ} \mathrm{C}$ incubation, the upper cells in the filter inserts were removed from the 12-well plates. Thus, only oligodendrocytes were involved in the subsequent lactate dehydrogenase (LDH) and Cell Counting Kit (CCK)-8 assays. Morphological changes in the primary microglia and oligodendrocytes were observed under a phase-contrast microscope (magnification, x200). All procedures were performed in triplicate independently in this experiment.

Low glucose/hypoxia stimulation. In conventional experiments, cells are cultured under normoxic conditions $\left(5 \% \mathrm{CO}_{2}, 20 \% \mathrm{O}_{2}\right.$ and $3.0 \mathrm{~g} / 1$ glucose). For the low glucose/hypoxia-mimicking assessments in the present study, the cells were cultured at $37^{\circ} \mathrm{C}$ in low glucose medium, in which glucose was partly replaced by $10 \%$ FBS under hypoxic conditions $\left(5 \% \mathrm{CO}_{2}, 1.5 \%\right.$ $\mathrm{O}_{2}$ and $1.4 \mathrm{~g} / \mathrm{l}$ glucose). To maintain cell viability, high glucose and oxygen recovery after exposure to low glucose/hypoxia is required. Thus, the cells suffered from low glucose/hypoxia for $0,2,4,6,8,10$ and $12 \mathrm{~h}$, followed by $24 \mathrm{~h}$ of high glucose and oxygen recovery treatment $\left(5 \% \mathrm{CO}_{2}, 30 \% \mathrm{O}_{2}\right.$ and $4.5 \mathrm{~g} / 1$ glucose).

NO production assessment. NO production from microglia was used as an indicator of microglial activation. Thus, the accumulation of $\mathrm{NO}^{2-}$, a stable end product of $\mathrm{NO}$ production, was assayed using the Griess reaction as previously reported (19). Mouse BV2 cells were plated on 96-well tissue culture plates (Greiner Bio-One $\mathrm{GmbH}$ ) at a density of $1 \times 10^{5}$ cells/200 $\mu 1$ medium. The cells were pre-incubated under low glucose/hypoxia conditions for $12 \mathrm{~h}$ followed by $24 \mathrm{~h}$ of high glucose and oxygen recovery incubation. Subsequently, the cell-free supernatants were assayed for NO accumulation using a Griess assay kit (Dojindo Molecular Technologies, Inc., Kumamoto, Japan) and read at $550 \mathrm{~nm}$ using a microplate reader (Multiscan MS; Thermo Labsystems, Helsinki, Finland).
ELISA. The secretion of inflammatory cytokines, including interleukin (IL)- 6 (cat. no. BMS603HS), interferon (IFN)- $\beta$ (cat. no. BMS606), IL-1 $\beta$ (cat. no. KMC0012) and tumor necrosis factor (TNF)- $\alpha$ (cat. no. BMS607HS), was detected using ELISA kits (Invitrogen; Thermo Fisher Scientific, Inc.). BV2 cells were pre-incubated in low glucose/hypoxia plus CPA $(1 \mu \mathrm{M})$, DPCPX (100 nM), CGS $(100 \mathrm{nM})$ or SCH $(100 \mathrm{nM})$ for $8 \mathrm{~h}$, and the conditioned media was collected for detection. All ELISA procedures were performed according to the manufacturer's protocol. Optical densities were determined by the measurement of indicator color shifts at $450 \mathrm{~nm}$ on a microplate reader (Multiscan MS).

LDH assay. Oligodendrocyte cell damage was determined by the colorimetric measurement of $\mathrm{LDH}$, the increased production of which is an indicator of damage. Cells were collected $24 \mathrm{~h}$ after co-culture. The LDH level was measured by a spectrophotometric enzyme assay using an LDH Assay kit (Wako Pure Chemical Industries, Ltd., Osaka, Japan). The assay was performed according to the manufacturer's protocol. In brief, LDH converts pyruvate into lactate that reduces the developer to a colored product with absorbance at $450 \mathrm{~nm}$ measured by a microplate reader (Multiscan MS).

CCK-8 assay. To assess cell proliferation, oligodendrocytes that had undergone low glucose/hypoxia plus CPA (1 $\mu \mathrm{M})$, DPCPX $(100 \mathrm{nM})$ CGS $(100 \mathrm{nM})$ or SCH $(100 \mathrm{nM})$ treatment for $12 \mathrm{~h}$ were seeded into 96-well cell culture plates (Corning Incorporated) at a concentration of $2 \times 10^{4}$ cells/well in a volume of $100 \mu \mathrm{l}$ and cultured overnight at $37^{\circ} \mathrm{C}$. CCK-8 reagents (Dojindo Molecular Technologies, Inc.) were added to each well at $0,2,4,6,8,10$ and $12 \mathrm{~h}$. The plates were then incubated for another $2 \mathrm{~h}$ at $37^{\circ} \mathrm{C}$ in the dark. The absorbency of the wells was measured at $450 \mathrm{~nm}$ using the Immuno-mini NJ-2300 microplate reader (InterMed, Tokyo, Japan).

Reverse transcription-quantitative polymerase chain reaction $(R T-q P C R)$ analysis. RT-qPCR analyses of inflammatory cytokines were performed as previously reported (20). A Transcriptor First Strand cDNA Synthesis kit (Roche Applied Science, Penzberg, Germany) was used according to the manufacturer's protocol. Briefly, microglial cultures were collected to extract total RNA using TRIzol reagent (Invitrogen; Thermo Fisher Scientific, Inc.), which was reverse transcribed with a combination of anchored-oligo(dT) and random primers that were included in the kit. Gene expression analysis was performed for four inflammatory cytokines (IL-6, IFN- $\beta$, IL- $1 \beta$ and TNF- $\alpha$ ) and the primers (5'-3') were as follows: IL-1 $\beta$ forward (F), CAACAACAAGTGATA TTCTCCATG and reverse (R), GATCCACACTCTCCA GCTGCA; TNF- $\alpha$ F, GCGGTGCCTATGTCTCAG and $R$, GCCATTTGGGAACTTCTCATC; IFN- $\beta$ F, CCCTAT GGAGATGACGGAGA and R, CTGTCTGCTGGTGGA GTTCA; IL-6 F, ATGAACTCCTTCTCCACAAGC and R, CTACATTTGCCGAAGAGCCCTCAGGCTGGACTG; and $\beta$-actin F, AGAGGGAAATCGTGCGTGAC and R, CAA TAGTGATGACCTGGCCGT. qPCR analysis was performed in a final volume of $10 \mu \mathrm{l}$ using $5 \mathrm{ng}$ cDNA/well and $5 \mu \mathrm{l}$ LightCycler $^{\circledR} 480$ Probes Master (Roche Applied Science). The reagents and samples were pipetted by an epMotion 5070 
Liquid Handling Robot (Eppendorf, Hamburg, Germany). The thermocycling conditions were as follows: Enzyme activation at $95^{\circ} \mathrm{C}$ for $10 \mathrm{~min} ; 45$ cycles of amplification at $95^{\circ} \mathrm{C}$ for $10 \mathrm{sec}, 60^{\circ} \mathrm{C}$ for $30 \mathrm{sec}$ and signal detection at $72^{\circ} \mathrm{C}$ for $1 \mathrm{sec}$; and cooling at $40^{\circ} \mathrm{C}$ for $30 \mathrm{sec}$. The expression levels were quantified using the $2^{-\Delta \Delta \mathrm{Cq}}$ method (21). For data normalization, the $\beta$-actin control was used. Interactive dot diagrams were used to represent the scale of the differences, and indicate the specificity and sensitivity values of the analyzed markers.

Western blotting. Western blotting was performed according to previously described method (22). Primary microglia were rinsed with ice-cold PBS and lysed in $8 \mathrm{M}$ urea, 2\% SDS, $100 \mathrm{mM}$ DTT and $375 \mathrm{mM}$ Tris (pH 6.8) by heating at $37^{\circ} \mathrm{C}$ for $2 \mathrm{~h}$. The proteins were resolved by 5-10\% SDS-PAGE. A total of $30 \mu \mathrm{g}$ protein was loaded in each lane. Following this, the gels were transferred to polyvinylidene difluoride membranes using a semidry transfer system. Subsequently, the membranes were immunoblotted overnight at $4^{\circ} \mathrm{C}$ with the following primary antibodies: Mouse anti-A2a (1:1,500; cat. no. ab79714; Abcam, Cambridge, MA, USA), rabbit anti-A1 (1:1,000; cat. no. ab82477; Abcam), rabbit anti-NF- $\mathrm{B}$ p65 (1:2,000; cat. no. 04-1008; EMD Millipore, Billerica, MA, USA), rabbit anti-phosphorylated (p)-NF- $\mathrm{B}$ p65 (1:1,000; cat. no. ab222494; Abcam), mouse anti-CREB antibody (1:1,000; cat. no. MAB5432; Millipore), mouse anti-phosphorylated CREB (1:1,000; cat. no. 05-667; Millipore), mouse anti-phosphorylated protein kinase C (p-PKC; 1:1,000; cat. no. ab75837; Abcam) and mouse anti protein kinase C (PKC; 1:1,000; cat. no. 05-983; Millipore). The membranes were then washed five times in $0.1 \%$ TBST and incubated with the secondary antibody [horseradish peroxidase-conjugated goat anti-mouse/rabbit immunoglobulin (Ig)G antibody; 1:1,000; cat. no. A0208 and A0216; Beyotime Institute of Biotechnology, Haimen, China] for $2 \mathrm{~h}$ at room temperature. The immunoreactive bands were developed using a chemiluminescent detection kit, visualized by ChemiDoc Imaging system (Bio-Rad Laboratories, Inc., Hercules, CA, USA) and quantified using ImageJ software (version 1.50i; National Institutes of Health, Bethesda, MD, USA). The membranes were then stripped and re-probed with a rabbit anti- $\alpha$-tubulin polyclonal primary antibody at $4^{\circ} \mathrm{C}$ overnight (1:1,000; cat. no. 11224-1-AP; Wuhan Sanying Biotechnology, Wuhan, China), followed by incubation with a horseradish peroxidase-conjugated goat anti-rabbit IgG antibody (1:1,000; cat. no. A0216; Beyotime Institute of Biotechnology) for $2 \mathrm{~h}$ at room temperature.

Statistical analysis. Statistical analyses were performed using GraphPad Prism (version 5.0; GraphPad Software, Inc., La Jolla, CA, USA). All experiments were repeated at least three times. All data were presented as the mean \pm standard error of the mean. Comparisons between groups were performed using one-way analysis of variance followed by a Bonferroni post hoc test where appropriate. $\mathrm{P}<0.05$ was considered to indicate a statistically significant difference.

\section{Results}

Imbalanced elevation and the antagonism between AIR and A2aR after low glucose/hypoxia in microglia. To mimic general ischemic injury, cells were cultured in low glucose and hypoxic conditions. Then, the expression of A1R and A2aR was measured in microglia exposed to low glucose/hypoxia for up to $10 \mathrm{~h}$. This revealed that low glucose/hypoxia induced an upregulation of $\mathrm{A} 1 \mathrm{R}$ and $\mathrm{A} 2 \mathrm{aR}$ at 4, 6, 8 and $10 \mathrm{~h}$ after exposure (Fig. 1A and B). Furthermore, the expression of A1R enhanced faster than that of $\mathrm{A} 2 \mathrm{aR}$ at 8 and $10 \mathrm{~h}$ after low glucose/hypoxia, suggesting an imbalance in A1R vs. A2aR expression. Next, agonists and antagonists of A1R and A2aR were applied to treat microglia that had been exposed to low glucose/hypoxia for $8 \mathrm{~h}$ (Fig. 1C and D). Interestingly, activation of A1R by CPA reduced the expression of A2aR, whereas inactivation of A1R by DPCPX did not notably increase A2aR expression. Conversely, activation of A2aR by CGS significantly reduced the expression of A1R, while the inhibition of A2aR with SCH did not significantly increase A1R expression. These data indicate an imbalance of A1R-A2aR expression after low glucose/hypoxia. However, this phenomenon requires verification under different metabolic tissue-specific conditions in vivo in the future.

Effects of $A 1 R$ and $A 2 a R$ on the activation of microglia. Compared to normal resting microglia, cells undergoing low glucose/hypoxia displayed a unique activation-associated morphology, including a larger and round soma, retracted projections and intercellular adhesion (Fig. 2A). To detect the effects of low glucose/hypoxia on the activation of microglia, the level of NO, an indicator of activated microglia, was measured in cultures exposed to low glucose/hypoxia for 2, 4, 6, 8, 10 and $12 \mathrm{~h}$. Low glucose/hypoxia induced an increased release of NO within $12 \mathrm{~h}$, peaking at $8 \mathrm{~h}$ (Fig. 2B). Furthermore, following an $8 \mathrm{~h}$ exposure to low glucose/hypoxia with agonists or antagonists of $\mathrm{A} 1 \mathrm{R}$ and $\mathrm{A} 2 \mathrm{aR}$, the $\mathrm{NO}$ concentration in the microglia cultures was assayed (Fig. 2C). Inactivation of A1R by DPCPX and activation of A2aR by CGS significantly reduced the NO level in microglial cultures under low glucose/hypoxia conditions. Notably, inhibition of A 2 aR with SCH significantly increased the NO level. The A1R agonist CPA had no significant effect on NO levels. These findings suggest that $\mathrm{A} 1 \mathrm{R}$ and $\mathrm{A} 2 \mathrm{aR}$ serve distinct roles in the activation of microglia under low glucose/hypoxia conditions.

Effects of $A 1 R$ and $A 2 a R$ on the production of $I L-6, I F N-\beta$, $I L-1 \beta$ and TNF- $\alpha$ by microglia. To determine whether activated microglia secrete proinflammatory cytokines, the protein and mRNAs level of IL-6, IFN- $\beta$, IL-1 $\beta$ and TNF- $\alpha$ were measured in cultures after low glucose/hypoxia treatment, and exposure to agonists or antagonists of A1R and $\mathrm{A} 2 \mathrm{aR}$, for $8 \mathrm{~h}$ (Table II and Fig. 3). The inhibition of A1R and activation of $\mathrm{A} 2 \mathrm{aR}$ reduced the concentration of IL- 6 , IL-1 $\beta$ and IFN- $\beta$ in cultures (Fig. 3A, B and D). By contrast, activation of $\mathrm{A} 1 \mathrm{R}$ or suppression of $\mathrm{A} 2 \mathrm{aR}$ increased the production of IL-6, IL-1 $\beta$ and TNF- $\alpha$ (Fig. 3A-C). Notably, the expression of IFN- $\beta$ mRNA was promoted by the A2aR antagonist SCH and reduced by its agonist CGS (Fig. $3 \mathrm{H}$ ). In addition, the A1R agonist CPA significantly enhanced the mRNA expression of IL-6, IL-1 $\beta$ and TNF- $\alpha$ (Fig. 3E-G). These results indicate that the activation of A1R and/or inactivation of A2aR cause the secretion of microglia-derived proinflammatory cytokines under low glucose/hypoxia conditions. 
A

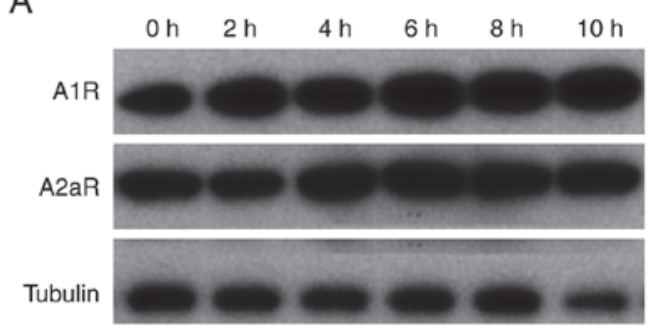

C

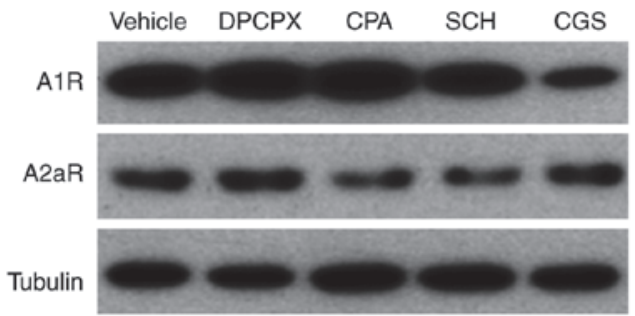

B

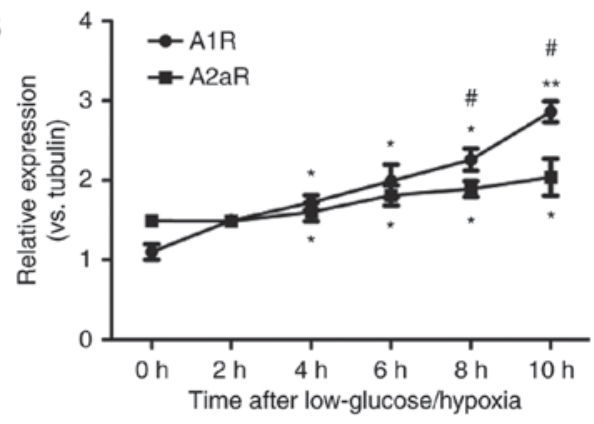

$\mathrm{D}$

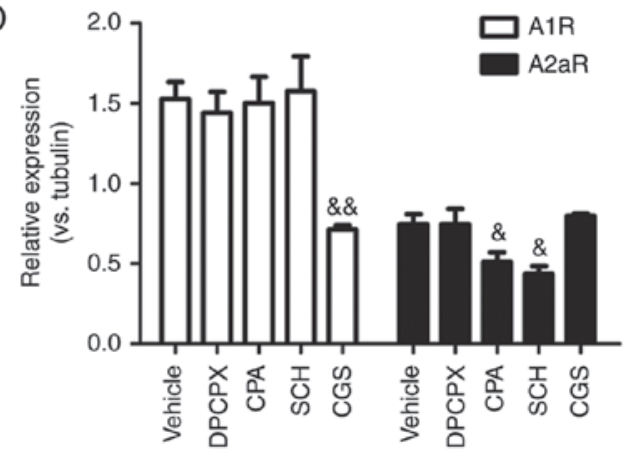

Figure 1. Imbalanced elevation and the antagonism between A1R and A2aR after low glucose/hypoxia in microglia. (A) Western blotting and (B) quantification of the expression of A1R and A2aR after exposure to low glucose/hypoxia for $0,2,4,6,8$ and $10 \mathrm{~h} .{ }^{*} \mathrm{P} \leq 0.05,{ }^{* *} \mathrm{P} \leq 0.01$ vs. the $0 \mathrm{~h}$ group; ${ }^{*} \mathrm{P} \leq 0.05$ vs. same time point in the A2aR group. (C) Western blotting and (D) quantification of the expression of A1R and A2aR after exposure to A1R and A2aR agonists and antagonists ( $\mathrm{n}=6 /$ group). ${ }^{\&} \mathrm{P} \leq 0.05$, ${ }^{\&}{ }^{\&} \mathrm{P} \leq 0.01$ vs. the vehicle group. A1R, adenosine A1 receptor; A2aR, adenosine A2a receptor.
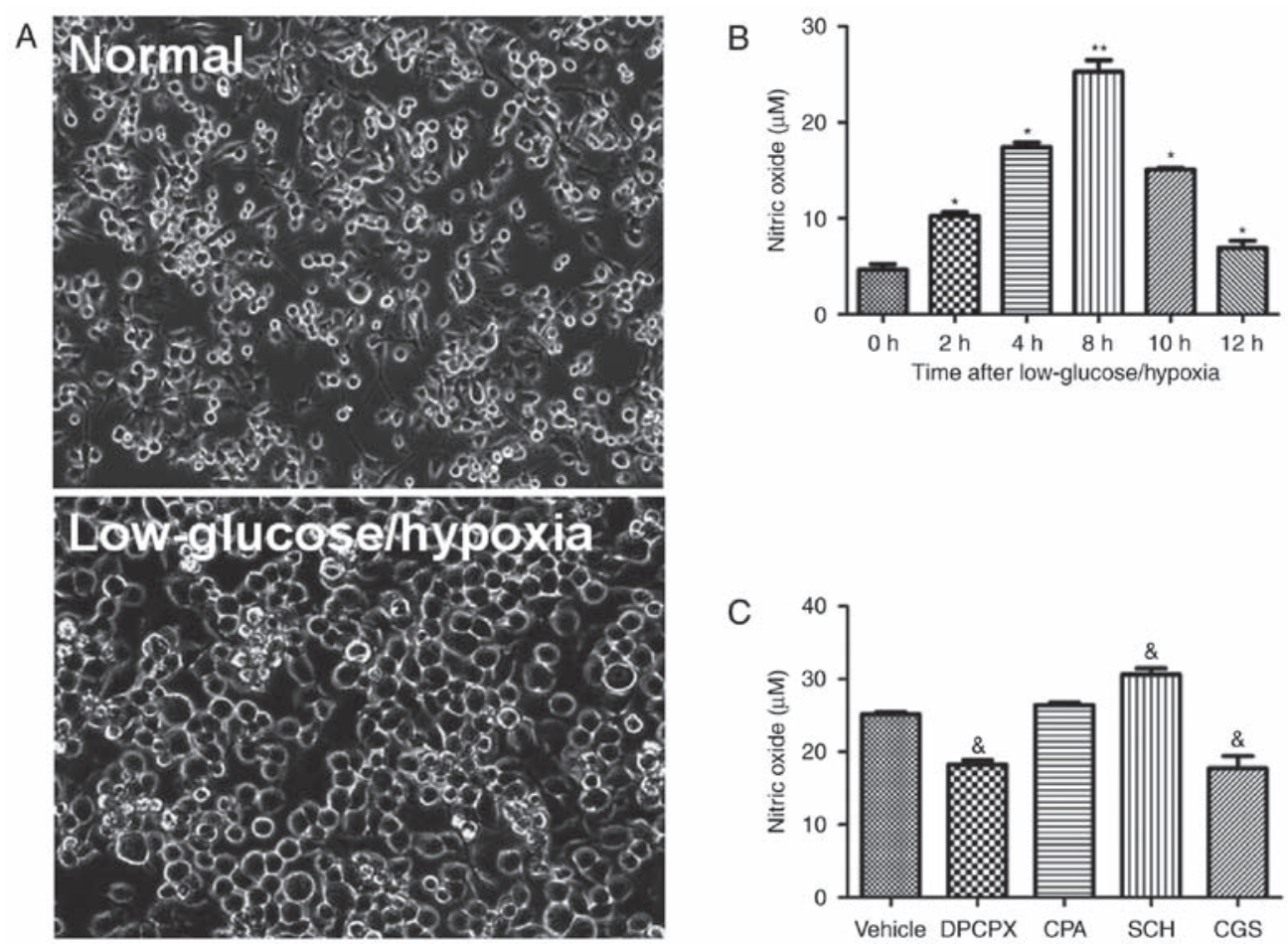

Figure 2. Effects of A1R and A2aR on the activation of microglia. (A) Phase-contrast microscopy images of microglia cell morphology under normal and low glucose/hypoxia conditions (magnification, x200). (B) Concentrations of NO, an indicator of microglial activation, at $0,2,4,6,8,10$ and $12 \mathrm{~h}$ after exposure to low glucose/hypoxia. (C) NO levels following treatment with A1R and A2aR agonists and antagonists (n=6/group). " $\mathrm{P} \leq 0.05$, ${ }^{* *} \mathrm{P} \leq 0.01 \mathrm{vs}$. the $0 \mathrm{~h}$ group; ${ }^{\circledR} \mathrm{P} \leq 0.05$ vs. the vehicle group. A1R, adenosine A1 receptor; A2aR, adenosine A2a receptor; NO, nitric oxide.

Effects of AlR and A2aR on oligodendrocyte damage. To further determine the effects of activated microglia on oligodendrocyte growth, a co-culture model of microglia and oligodendrocytes was used. The cytotoxicity induced by microglia-derived inflammatory cytokines was investigated by an LDH release assay and cell viability was measured using a 
Table II. Effects of the A1R and A2aR agonists and antagonists on proinflammatory cytokine levels.

\begin{tabular}{|c|c|c|c|c|}
\hline \multirow[b]{2}{*}{ Cytokine } & \multicolumn{4}{|c|}{ Drug } \\
\hline & DPCPX (A1R inhibitor) & CPA (A1R activator) & $\mathrm{SCH}$ (A2aR inhibitor) & CGS (A2aR activator) \\
\hline IL-6 protein & Downregulation $^{\mathrm{a}}$ & Upregulation $^{\mathrm{b}}$ & Upregulation $^{\mathrm{a}}$ & Downregulation $^{\mathrm{a}}$ \\
\hline IL-6 mRNA & - & Upregulation $^{\mathrm{a}}$ & Upregulation $^{\mathrm{a}}$ & Downregulation $^{\mathrm{a}}$ \\
\hline IL- $1 \beta$ protein & Downregulation $^{\mathrm{a}}$ & Upregulation $^{\mathrm{a}}$ & Upregulation $^{\mathrm{a}}$ & Downregulation $^{\mathrm{a}}$ \\
\hline IL-1 $\beta$ mRNA & - & Upregulation $^{\mathrm{b}}$ & - & - \\
\hline TNF- $\alpha$ protein & - & Upregulation $^{\mathrm{a}}$ & Upregulation $^{\mathrm{a}}$ & Downregulation $^{\mathrm{a}}$ \\
\hline TNF- $\alpha$ mRNA & - & Upregulation $^{\mathrm{a}}$ & - & Downregulation $^{\mathrm{a}}$ \\
\hline IFN- $\beta$ protein & - & Upregulation $^{\mathrm{b}}$ & Upregulation $^{\mathrm{a}}$ & Downregulation $^{\mathrm{a}}$ \\
\hline IFN- $\beta$ mRNA & Downregulation $^{\mathrm{a}}$ & - & Upregulation $^{\mathrm{a}}$ & - \\
\hline
\end{tabular}

A1R, adenosine A1 receptor; A2aR, adenosine A2a receptor; IL, interleukin; IFN, interferon; TNF, tumor necrosis factor. ${ }^{\mathrm{a} P} \leq 0.05$, ${ }^{\mathrm{b}} \mathrm{P} \leq 0.01 \mathrm{vs}$. the vehicle group.
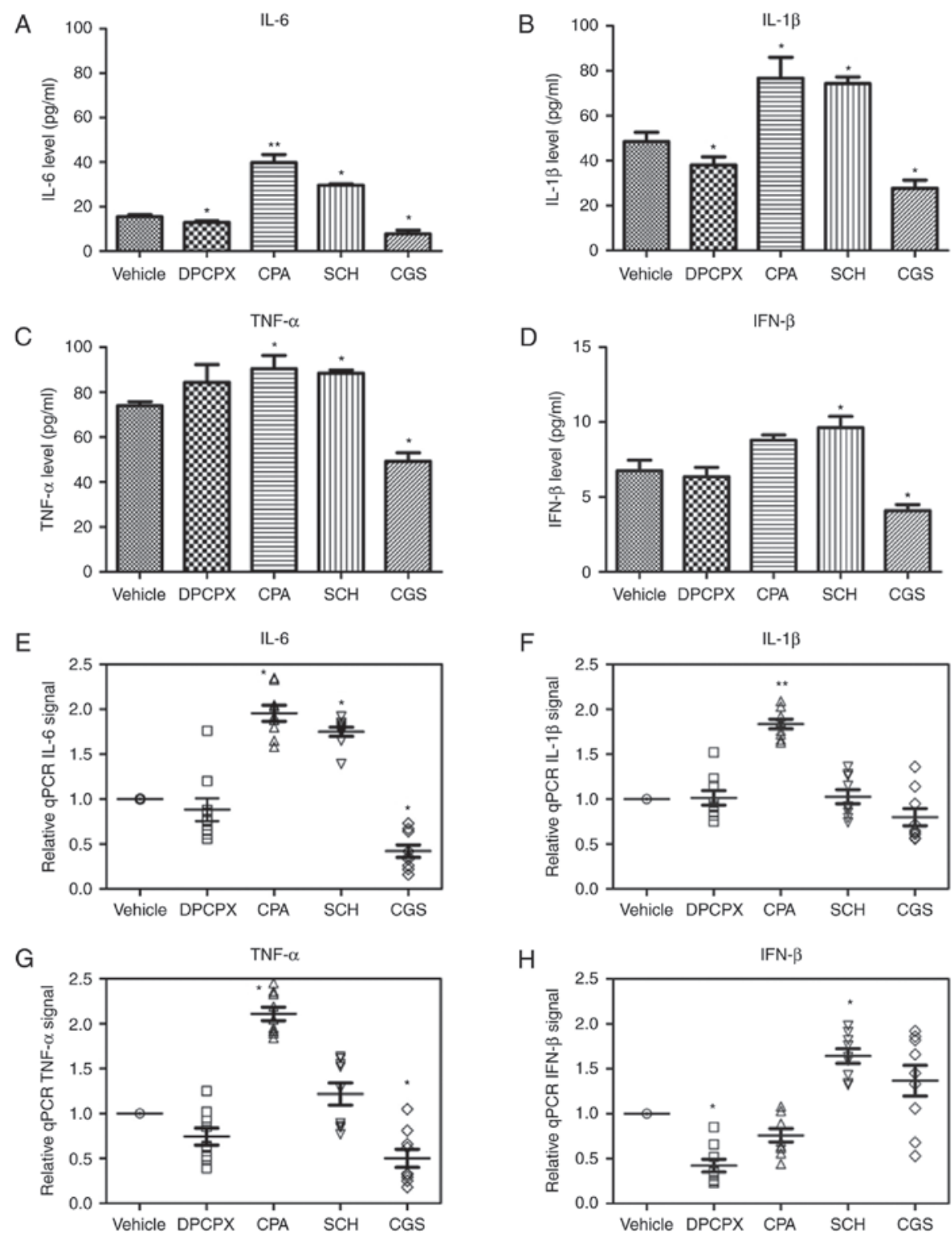

Figure 3. Effects of A1R and A2aR on the production of IL-6, IFN- $\beta$, IL-1 $\beta$ and TNF- $\alpha$ by microglia. The concentration of (A) IL-6, (B) IL-1 $\beta$, (C) TNF- $\alpha$ and (D) IFN- $\beta$ after exposure to A1R and A2aR agonists and antagonists ( $n=9 /$ group) was detected by ELISAs. The mRNA levels of (E) IL-6, (F) IL-1 $\beta,(\mathrm{G})$ TNF- $\alpha$ and $(\mathrm{H})$ IFN- $\beta$ after exposure to A1R and A2aR agonists and antagonists ( $\mathrm{n}=9$ /group) were determined by reverse-transcription quantitative polymerase chain reaction analysis. "P $\leq 0.05,{ }^{* *} \mathrm{P} \leq 0.01$ vs. the vehicle group. A1R, adenosine A1 receptor; A2aR, adenosine A2a receptor; IL, interleukin; IFN, interferon; TNF, tumor necrosis factor. 

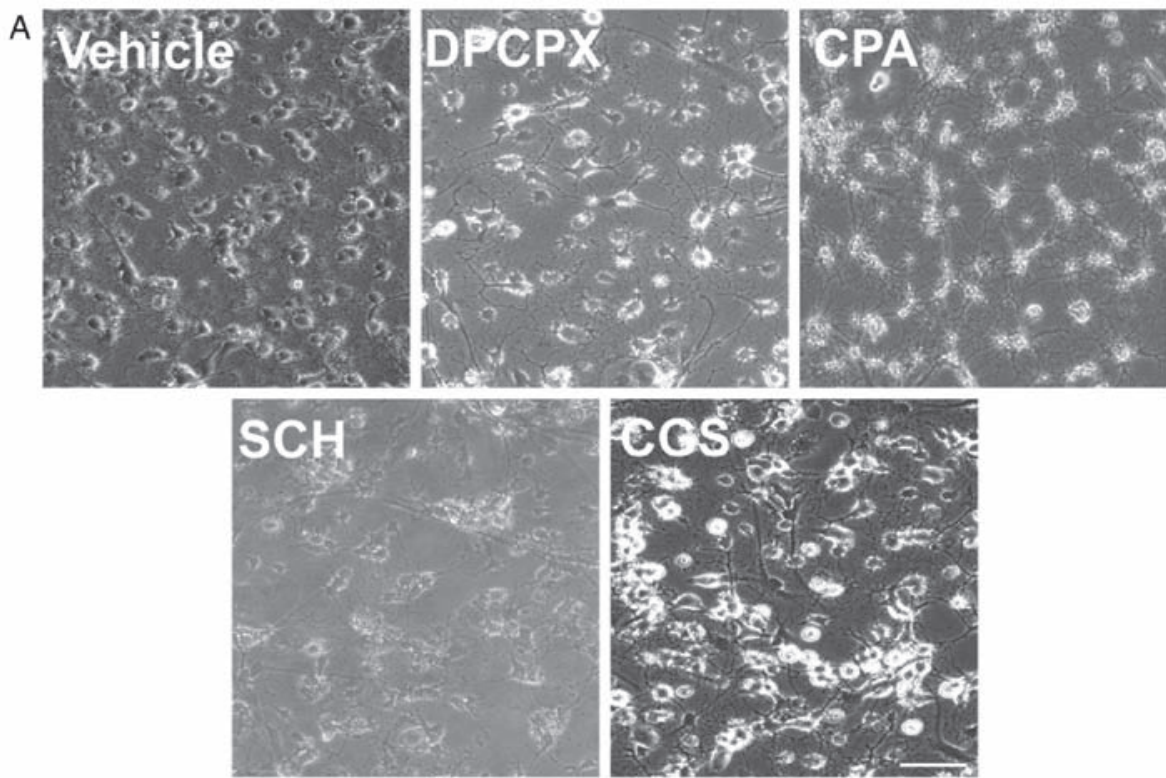

B
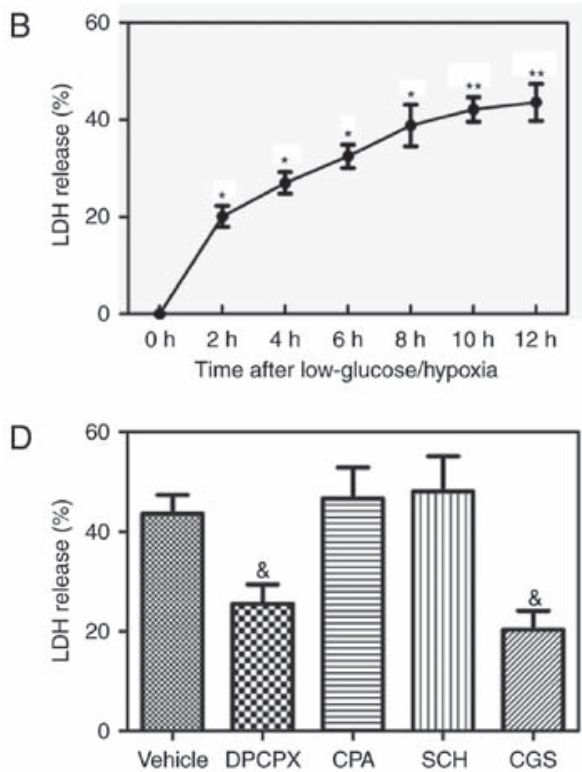

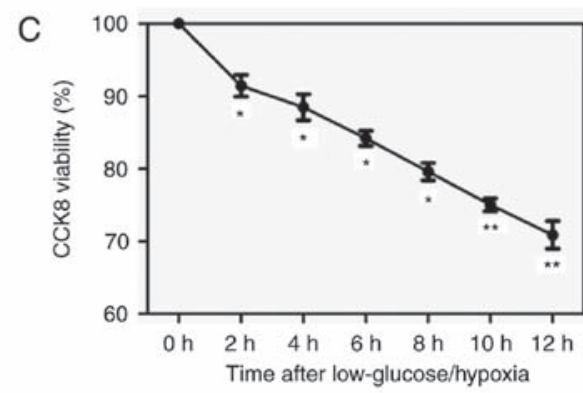

$\mathrm{E}$

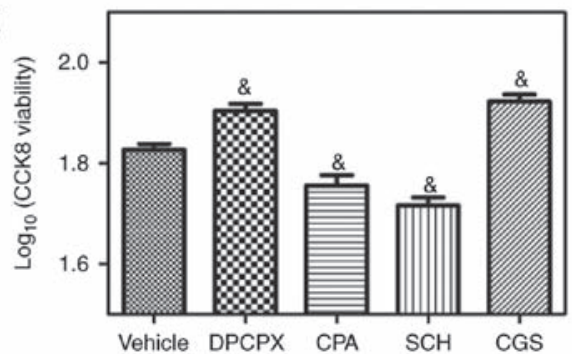

Figure 4. Effects of A1R and A2aR on oligodendrocyte damage. (A) Phase-contrast microscopy images of oligodendrocyte cell morphology (magnification, $\mathrm{x} 200$ ) after exposure to A1R and A2aR agonists and antagonists. Changes in the (B) LDH released and (C) CCK-8 assay-measured viability of oligodendrocytes at $0,2,4,6,8,10$ and $12 \mathrm{~h}$ after exposure to low glucose/hypoxia. (D) LDH release (E) viability of oligodendrocytes after exposure to A1R and A2aR agonists and antagonists ( $\mathrm{n}=3$ /group). ${ }^{*} \mathrm{P} \leq 0.05,{ }^{* *} \mathrm{P} \leq 0.01$ vs. the $0 \mathrm{~h}$ group; ${ }^{\circledR} \mathrm{P} \leq 0.05$ vs. the vehicle group. A1R, adenosine A1 receptor; A2aR, adenosine A2a receptor; LDH, lactate dehydrogenase; CCK-8, Cell Counting Kit-8.

CCK-8 assay. Reduced cell density and processes were observed in the low glucose/hypoxia stimulated groups (Fig. 4A). Low glucose/hypoxia caused a significant increase in LDH release and significantly decreased the viability of oligodendrocytes within $12 \mathrm{~h}$ compared with the vehicle group (Fig. 4B and C). Inactivation of A1R by DPCPX and activation of A2aR by CGS significantly reduced LDH release and significantly increased viability within $12 \mathrm{~h}$ compared with the vehicle group (Fig. 4D and E). Although activation of A1R by CPA and inactivation $\mathrm{A} 2 \mathrm{aR}$ by $\mathrm{SCH}$ did not further enhance $\mathrm{LDH}$ release, they significantly reduced cell viability compared with the vehicle group (Fig. 4D and E). These data suggest that A1R and $\mathrm{A} 2 \mathrm{aR}$ serve distinct roles in oligodendrocyte impairment. The inactivation of A1R and activation of A2aR may be an effective way of reducing oligodendrocyte damage after low glucose/hypoxia.

$N F-\kappa B$ and $C R E B$ are involved in the effects of the interaction between $A 1 R$ and $A 2 a R . N F-\kappa B$ and CREB are critical transcriptional regulators of inflammation. Thus, whether an A1R-A2aR imbalance could affect the expression of $\mathrm{NF}-\kappa \mathrm{B}$ and CREB in microglia was investigated (Fig. 5). Compared with the vehicle group, inactivation of A1R by DPCPX and activation of A2aR by CGS significantly reduced the phosphorylation of NF- $\kappa$ B p65 (Fig. 5B). Paradoxically, activation of A1R also significantly reduced the expression of $\mathrm{p}-\mathrm{NF}-\kappa \mathrm{B}$ (Fig. 5B). Inactivation of A2aR by $\mathrm{SCH}$ significantly enhanced the expression of NF- $\kappa \mathrm{B}$ but not $\mathrm{p}-\mathrm{NF}-\kappa \mathrm{B}$ (Fig. $5 \mathrm{~B}$ and $\mathrm{C}$ ). 
A
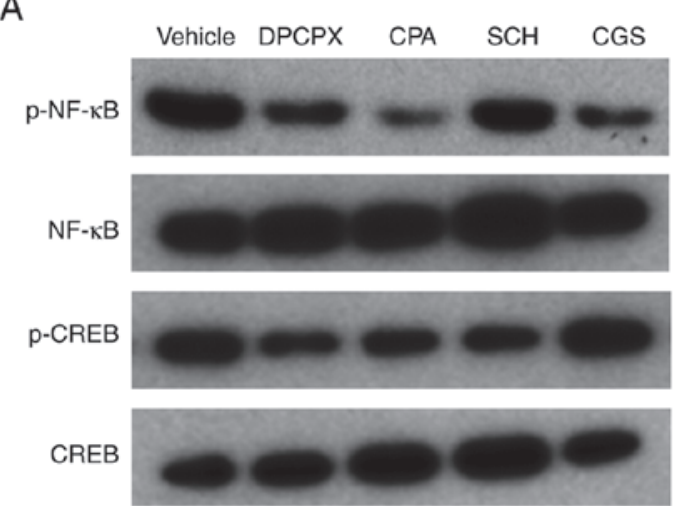

p-PKC

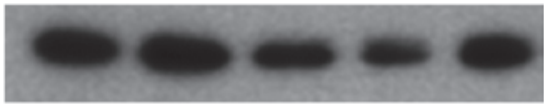

PKC

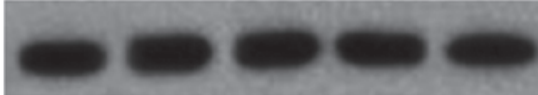

Tubulin

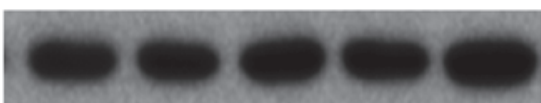

D

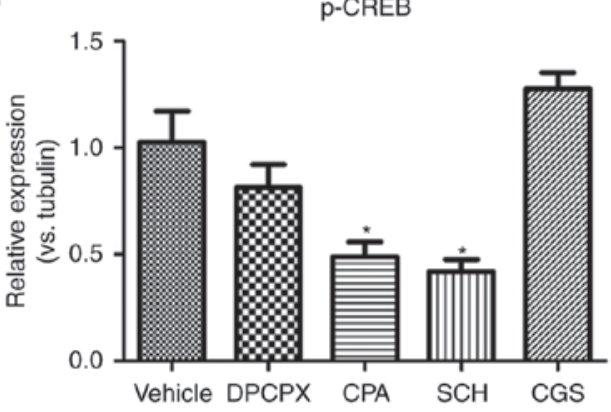

F

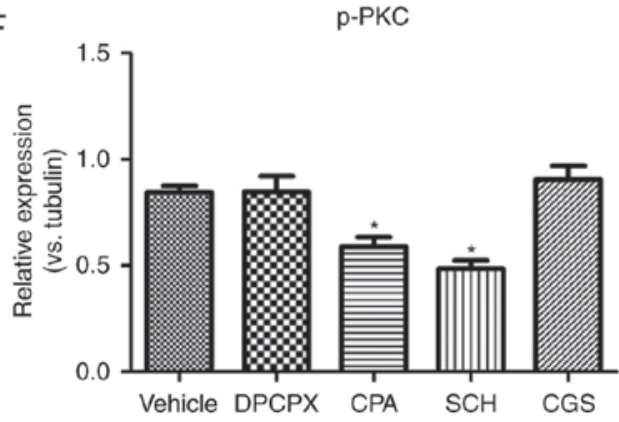

B
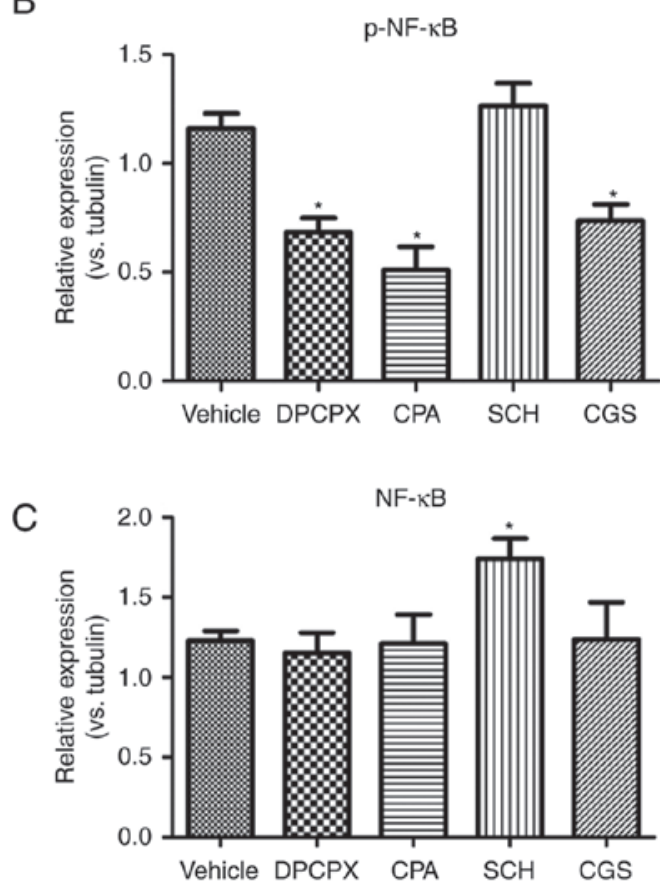

E

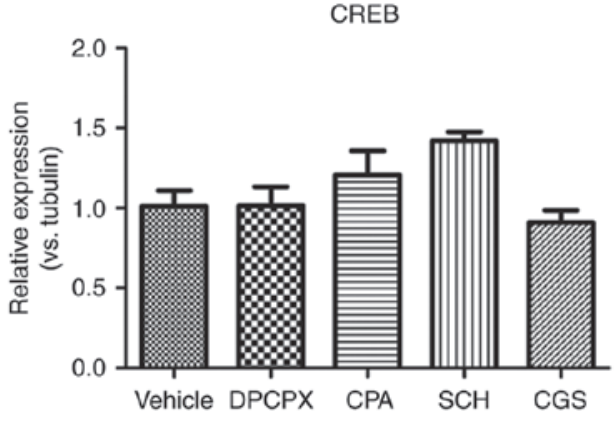

G

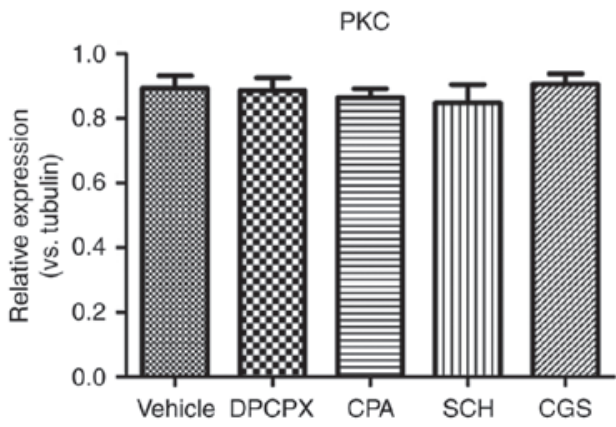

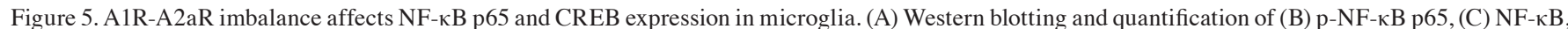
(D) p-CREB, (E) CREB, (F) p-PKC and (G) PKC in microglia exposed to low glucose/hypoxia plus A1R and A2aR agonists and antagonists (n=3/group). ${ }^{\text {"P }} \leq 0.05$ vs. the vehicle group. A1R, adenosine A1 receptor; A2aR, adenosine A2a receptor; NF, nuclear factor; CREB, cyclic adenosine monophosphate response element binding protein; PKC, protein kinase C.

Activation of A1R by CPA and inactivation of A2aR by $\mathrm{SCH}$ significantly reduced the protein levels of $\mathrm{p}-\mathrm{PKC}$ and p-CREB (Fig. 5D and F). However, the expression of PKC and CREB was not significantly changed by any of the drugs (Fig. 5E and G).

Together, as illustrated in the schematic in Fig. 6, an imbalanced elevation of $\mathrm{A} 1 \mathrm{R}$ and $\mathrm{A} 2 \mathrm{aR}$ can result in the activation of microglia under low glucose/hypoxia conditions. Low glucose/hypoxia induces the phosphorylation of NF- $\kappa \mathrm{B}$ p 65 and CREB, promoting the release of inflammatory cytokines and causing oligodendrocyte damage. Therefore, rebalancing A1R-A2aR via the inactivation of A1R and activation of A2aR may inhibit this microglia-mediated immune cascade and prevent the damage of oligodendrocytes under low glucose/hypoxia conditions. 


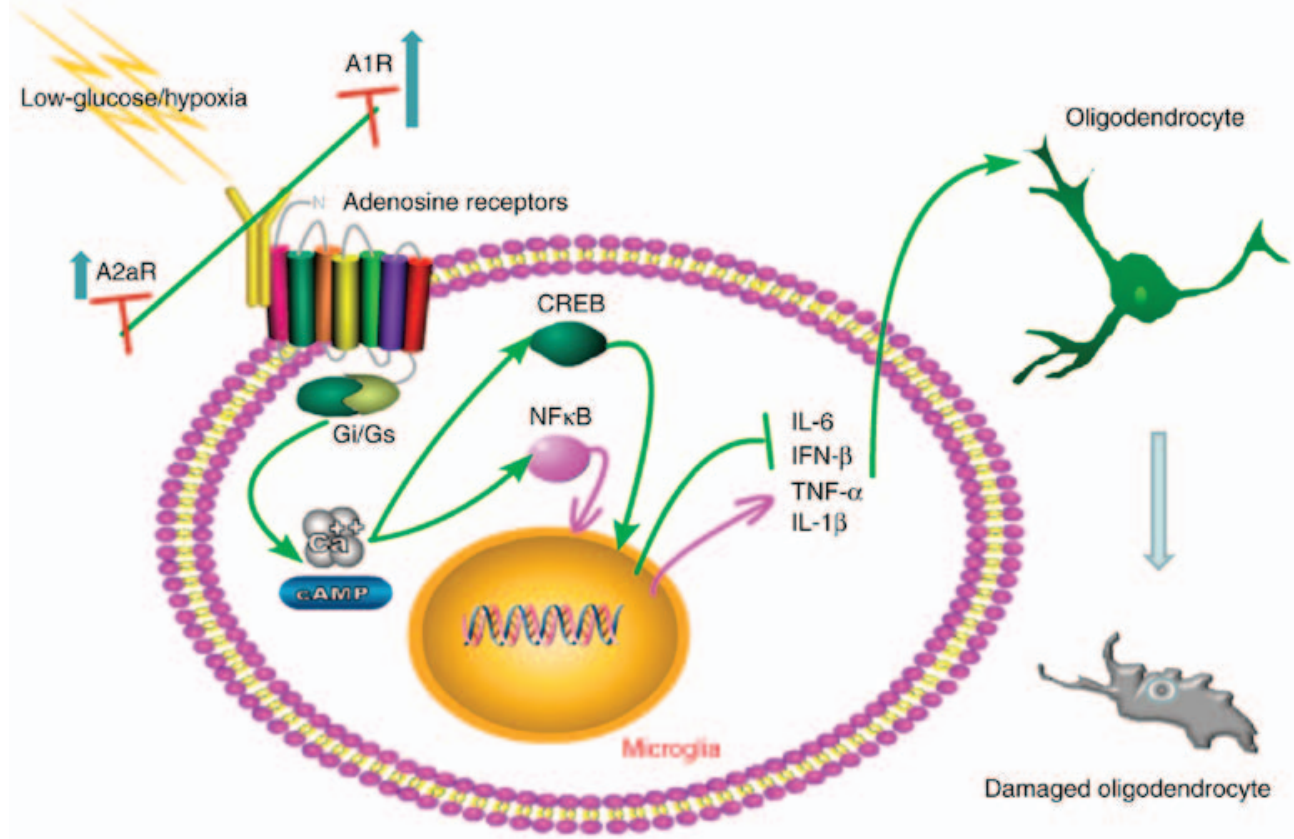

Figure 6. Schematic of the mechanisms by which A1R-A2aR imbalance activates microglia and damages oligodendrocytes under low glucose/hypoxia conditions. Low glucose/hypoxia stimulation causes an imbalance in elevation of A1R and A2a, with A1R levels increasing faster than A2aR levels. This imbalance triggers activation of the microglia and the following immune cascade. Mechanisms proposed to be involved include the inflammatory modulation of adenosine receptors coupled to $\mathrm{G}_{\mathrm{i}} / \mathrm{G}_{\mathrm{s}}$ proteins. Overexpressed A1R activates cAMP or $\mathrm{Ca}^{2+}$, promoting the phosphorylation of NF- $\mathrm{kB}$ p65 and CREB. Activation of these transcription factors regulates the release of inflammatory cytokines from the microglia, causing oligodendrocyte damage. A1R, adenosine A1 receptor; A2aR, adenosine A2a receptor; NF, nuclear factor; cAMP, cyclic adenosine monophosphate; CREB, cAMP response element binding protein; IL, interleukin; IFN, interferon; TNF, tumor necrosis fact.

\section{Discussion}

The present study investigated the role of A1R-A2aR imbalance in low glucose/hypoxia-induced microglial activation. The results indicated that an imbalance of A1R-A2aR serves an important role in the onset of microglial activation and inflammation after exposure to a low glucose/hypoxia in a NF- $\kappa B-$ and CREB-dependent manner. In addition, an A1R antagonist and $\mathrm{A} 2 \mathrm{aR}$ agonist were applied to rebalance A1R-A2aR, which suppressed microglial activation and exhibited anti-inflammatory activity. Taking into account the results of our previous study, which identified that A2aR in bone marrow-derived dendritic cells is an important modulator of chronic cerebral hypoperfusion-induced WMLs (14), an A1R-A2aR imbalance may have important consequences for neuroinflammation and serve a role in the pathology of numerous CNS diseases.

The release of ATP in the brain serves an irreplaceable role in recruiting and formatting microglia to mount neuroinflammatory responses after hypoxia (15). This response involves the activation of different ATP purinergic 2 receptors, as well as ARs (16). However, the distinct role and interaction of these ARs remains unknown. The present study demonstrated that the activation of A2aR inhibits A1R in microglia, and vice versa. This antagonistic association between $\mathrm{A} 1 \mathrm{R}$ and $\mathrm{A} 2 \mathrm{aR}$ has been identified in previous studies. For example, A2R inhibits neutrophil adhesion to the endothelial layer, thereby blocking inflammatory initiation, while A1R enhances this process (17). Activation of presynaptic A1R suppresses excitatory transmission by reducing the probability of release, whereas A2aR exerts a facilitating effect on synaptic transmission by inhibiting A1R-mediated suppression (18). The neuromodulatory role of adenosine relies on a balanced activation of inhibitory A1R and facilitating A2aR (19). The current study revealed that the activation of A2aR with CGS attenuated inflammatory activity and improved oligodendrocyte viability. However, certain studies have reported that inhibition of A2aR alleviates the long-term burden of brain disorders in different neurodegenerative and psychiatric conditions, including ischemia, epilepsy, Parkinson's disease and Alzheimer's disease $(19,22,23)$. The distinct role of A2aR in different pathological scenarios requires further study. By contrast, A1R acts as a regulator that effectively controls neurodegeneration if activated in the temporal vicinity of brain damage $(11,24)$. In the present study, the upregulation of A1R was presumably responsible for the activation of microglia. This in vitro finding is in agreement with the results of a previous in vivo study of $\mathrm{A}^{-1-}$ mice with neonatal brain hypoxic ischemia (25). Intriguingly, pharmacological preconditioning with an A1R agonist has been demonstrated to suppress the cellular immune response through an A2aR-dependent mechanism (26). These results suggest that targeting $\mathrm{A} 1 \mathrm{R}$ and $\mathrm{A} 2 \mathrm{aR}$ is a promising approach for researching and treating neuroinflammation.

The distinct effects of A1R and A2aR allude to different mechanisms of control for microglial activation. This mechanism may be similar to the process observed in neurons, in which the interaction between $\mathrm{A} 1 \mathrm{R}$ and $\mathrm{A} 2 \mathrm{aR}$ modulates neurotransmitter transporters via coupling to $\mathrm{G}_{\mathrm{i}} / \mathrm{G}_{\mathrm{s}}$ proteins $(27,28)$. A1R and A2aR may closely interact in such a way that the A1R is often inhibitory and couples to $\mathrm{G}_{\mathrm{i}} / \mathrm{G}_{\mathrm{o}}$ proteins, while $A 2 \mathrm{aR}$ is usually coupled to $\mathrm{G}_{\mathrm{s}}$ proteins, enhancing cAMP accumulation and PKA activity (29). Furthermore, the present study revealed 
that the A1R antagonist DPCPX reduced the phosphorylation of NF- $\kappa \mathrm{B}$ p 65 , and the production of IL-1 $\beta$ and TNF- $\alpha$. Conversely, $\mathrm{NF}-\kappa \mathrm{B}$ has been reported to regulate $\mathrm{A} 2 \mathrm{aR}$ gene transcription through a mechanism involving IL-1 $\beta$ and TNF- $\alpha$ (29). A2aR is able to enhance CREB phosphorylation via raising cAMP levels. Furthermore, p-CREB competitively binds with CREB binding protein, a ligand of $\mathrm{NF}-\kappa \mathrm{B}$ p65, and inhibits NF-KB transcription (30). In addition, the NO/cyclic guanosine monophosphate/protein kinase G/ATP-sensitive $\mathrm{K}^{+}$ channel and the p38 mitogen-activated protein kinase signaling pathways can modulate CREB and NF-kB expression, insinuating a more complex signaling interaction between $\mathrm{A} 1 \mathrm{R}$ and $\mathrm{A} 2 \mathrm{aR}$ (31-34). These data indicate that NF- $\mathrm{B}$ and CREB can be exploited as important nodes of the signaling network for the dissection of the interaction between $\mathrm{A} 1 \mathrm{R}$ and $\mathrm{A} 2 \mathrm{aR}$.

The present study had several limitations. Firstly, a co-culture model of microglia and oligodendrocytes was used to investigate the effects of microglial-derived inflammatory cytokines on oligodendrocyte damage. However, an in vivo study should be performed in the future. Secondly, despite an association between A1R-A2aR imbalance and microglial activation after low glucose/hypoxia being demonstrated in the current study, the underlying mechanisms require elucidation. Thirdly, the mechanisms of the production of inflammatory cytokines from microglia are sophisticated and individualized; thus, additional signaling pathways apart from NF- $\kappa \mathrm{B}$ and CREB should be explored. Lastly, A1R and A2aR have been reported to form complicated tetrameric heteromers in astrocytes and neurons using bioluminescence resonance energy transfer (BRET) and fluorescence resonance energy transfer (FRET) methods $(13,35)$. Thus, whether A1R-A2aR heteromerization also occurs in microglia requires more direct evidence by means of BRET or FRET in the future.

In conclusion, the present study demonstrated that there is an imbalanced elevation of A1R-A2aR in microglia after exposure to low glucose/hypoxia, which initiates the release of inflammatory cytokines via modulation of $N F-\kappa B$ and CREB phosphorylation, thus contributing to oligodendrocyte damage. These results implicate an imbalance of A1R-A2aR in white matter impairment-induced demyelinating diseases. Suppression of A1R and activation of A2aR may be beneficial for rebalancing A1R-A2aR, thereby providing novel therapeutic strategies for the treatment of excessive nerve inflammation.

\section{Acknowledgements}

The present study was supported by the National Natural Science Foundation of China (grant nos. 81171113 and 81571129) and the Natural Science Foundation of Chongqing (grant no. CSTC 2011BA5012).

\section{Competing interests}

The authors declare that there are no competing interests.

\section{References}

1. Kaur $\mathrm{C}$ and Ling EA: Periventricular white matter damage in the hypoxic neonatal brain: Role of microglial cells. Prog Neurobiol 87: 264-280, 2009.
2. Pang Y, Campbell L, Zheng B, Fan L, Cai Z and Rhodes P: Lipopolysaccharide-activated microglia induce death of oligodengroctye progenitor cells and impede their development, Neuroscience 166: 464-475, 2010.

3. Steinman L: No quiet surrender: Molecular guardians in multiple sclerosis brain. J Clin Invest 125: 1371-1378, 2015.

4. Mittelbronn M, Dietz K, Schluesener HJ and Meyermann R: Local distribution of microglia in the normal adult human central nervous system differs by up to one order of magnitude. Acta Neuropathol 101: 249-255, 2001.

5. Yenari MA, Kauppinen TM and Swanson RA: Microglial activation in stroke: Therapeutic targets. Neurotherapeutics 7: 378-391, 2010.

6. Yu Y, Yu Z, Xie M, Wang W and Luo X: Hv1 proton channel facilitates production of ROS and pro-inflammatory cytokines in microglia and enhances oligodendrocyte progenitor cells damage from oxygen-glucose deprivation in vitro. Biochem Biophys Res Commun: Jul 1, 2017 (Epub ahead of print).

7. Espinoza-Rojo M,Iturralde-RodríguezKI,Chánez-Cárdenas ME, Ruiz-Tachiquín ME and Aguilera P: Glucose transporters regulation on ischemic brain: Possible role as therapeutic target. Cent Nerv Syst Agents Med Chem 10: 317-235, 2010.

8. Butt AM: ATP: A ubiquitous gliotransmitter integrating neuron-glial networks. Semin Cell Dev Biol 22: 205-213, 2011.

9. Takenouchi T, Tsukimoto M, Iwamaru Y, Sugama S, Sekiyama K, Sato M, Kojima S, Hashimoto M and Kitani H: Extracellular ATP induces unconventional release of glyceraldehyde-3-phosphate dehydrogenase from microglial cells. Immunol Lett 167: 116-124, 2015.

10. Antonioli L, Blandizzi C, Pacher P and Haskó G: Immunity, inflammation and cancer: A leading role for adenosine. Nat Rev Cancer 13: 842-857, 2013

11. Serchov T, Clement HW, Schwarz MK, Iasevoli F, Tosh DK, Idzko M, Jacobson KA, de Bartolomeis A, Normann C, Biber K and van Calker D: Increased signaling via adenosine A1 receptors, sleep deprivation, imipramine, and ketamine inhibit Depressive-like behavior via induction of Homerla. Neuron 87: 549-562, 2015.

12. Di Virgilio F, Ceruti S, Bramanti P and Abbracchio MP: Purinergic signalling in inflammation of the central nervous system. Trends Neurosci 32: 79-87, 2009.

13. Cristóvão-Ferreira S, Navarro G, Brugarolas M, Pérez-Capote K, Vaz SH, Fattorini G, Conti F, Lluis C, Ribeiro JA, McCormick PJ, et al: A1R-A2AR heteromers coupled to Gs and $\mathrm{Gi} / 0$ proteins modulate GABA transport into astrocytes. Purinergic Signal 9: 433-449, 2013.

14. Ran H, Duan W, Gong Z, Xu S, Zhu H, Hou X, Jiang L, He Q and Zheng J: Critical contribution of adenosine A2a receptors in bone marrow-derived cells to white matter lesions induced by chronic cerebral hypoperfusion. J Neuropathol Exp Neurol 74: 305-318, 2015 .

15. Burnstock G, Fredholm BB and Verkhratsky A: Adenosine and ATPreceptors in the brain.Curr Top Med Chem 11:973-1011,2011.

16. Rodrigues RJ, Tomé AR and Cunha RA: ATP as a multi-target danger signal in the brain. Front Neurosci 9: 148, 2015.

17. He W, Mazumder A, Wilder T and Cronstein BN: Adenosine regulates bone metabolism via $\mathrm{A} 1, \mathrm{~A} 2 \mathrm{~A}$, and $\mathrm{A} 2 \mathrm{~B}$ receptors in bone marrow cells from normal humans and patients with multiple myeloma. FASEB J 27: 3446-3454, 2013.

18. Seki Y, Kato TA, Monji A, Mizoguchi Y, Horikawa H, Sato-Kasai M, Yoshiga D and Kanba S: Pretreatment of aripiprazole and minocycline, but not haloperidol, suppresses oligodendrocyte damage from interferon- $\gamma$-stimulated microglia in co-culture model. Schizophr Res 151: 20-28, 2013.

19. Gomes CV, Kaster MP, Tomé AR, Agostinho PM and Cunha RA: Adenosine receptors and brain diseases: Neuroprotection and neurodegeneration. Biochim Biophys Acta 1808: 1380-1399, 2011.

20. Latini S and Pedata F: Adenosine in the central nervous system: Release mechanisms and extracellular concentrations. J Neurochem 79: 463-484, 2001.

21. Livak KJ and Schmittgen TD: Analysis of relative gene expression data using real-time quantitative PCR and the $2^{-\Delta \Delta C \mathrm{~T}}$ method. Methods 25: 402-408, 2001.

22. Rudolphi KA, Schubert P, Parkinson FE and Fredholm BB: Adenosine and brain ischemia. Cerebrovasc Brain Metab Rev 4: 346-369, 1992.

23. Boison D: Adenosine kinase, epilepsy and stroke: Mechanisms and therapies. Trends Pharmacol Sci 27: 652-658, 2006.

24. Dauer W and Przedborski S: Parkinson's disease: Mechanisms and models. Neuron 39: 889-909, 2003. 
25. Masino SA, Li T, Theofilas P, Sandau US, Ruskin DN, Fredholm BB, Geiger JD, Aronica E and Boison D: A ketogenic diet suppresses seizures in mice through adenosine A1 receptors. J Clin Invest 121: 2679-2683, 2011.

26. Winerdal M, Winerdal ME, Wang YQ, Fredholm BB, Winqvist $\mathrm{O}$ and Adén $\mathrm{U}$ : Adenosine A1 receptors contribute to immune regulation after neonatal hypoxic ischemic brain injury. Purinergic Signal 12: 89-101, 2016.

27. Naamani O, Chaimovitz C and Douvdevani A: Pharmacological preconditioning with adenosine $\mathrm{A}_{1}$ receptor agonist suppresses cellular immune response by an $\mathrm{A}_{2}$ receptor dependent mechanism. Int Immunopharmacol 20: 205-212, 2014.

28. Zhang P, Bannon NM, Ilin V, Volgushev M and Chistiakova M: Adenosine effects on inhibitory synaptic transmission and excitation-inhibition balance in the rat neocortex. J Physiol 593: 825-841, 2015

29. Fenton RA and Dobson JG Jr: Adenosine $A_{1}$ and $A_{2 A}$ receptor effects on G-protein cycling in beta-adrenergic stimulated ventricular membranes. J Cell Physiol 213: 785-792, 2007.

30. Morello S, Ito K, Yamamura S, Lee KY, Jazrawi E, Desouza P, Barnes P, Cicala C and Adcock IM: IL-1 beta and TNF-alpha regulation of the adenosine receptor $\left(\mathrm{A}_{2 \mathrm{~A}}\right)$ expression: Differential requirement for NF-kappa $\mathrm{B}$ binding to the proximal promoter. J Immunol 177: 7173-7183, 2006.
31. Loram LC, Taylor FR, Strand KA, Harrison JA, Rzasalynn R, Sholar P, Rieger J, Maier SF and Watkins LR: Intrathecal injection of adenosine $2 \mathrm{~A}$ receptor agonists reversed neuropathic allodynia through protein kinase (PK)A/PKC signaling. Brain Behav Immun 33: 112-122, 2013.

32. Yang Y, Wang H, Lv X, Wang Q, Zhao H, Yang F, Yang Y and Li J: Involvement of cAMP-PKA pathway in adenosine $\mathrm{A}_{1}$ and $\mathrm{A}_{2 \mathrm{~A}}$ receptor-mediated regulation of acetaldehyde-induced activation of HSCs. Biochimie 115: 59-70, 2015.

33. Lima FO, Souza GR, Verri WJ Jr, Parada CA, Ferreira SH, Cunha FQ and Cunha TM: Direct blockade of inflammatory hypernociception by peripheral A1 adenosine receptors: Involvement of the NO/cGMP/PKG/KATP signaling pathway. Pain 151: 506-515, 2010.

34. Haack KK, Mitra AK and Zucker IH: NF-кB and CREB are required for angiotensin II type 1 receptor upregulation in neurons. PLoS One 8: e78695, 2013.

35. Ciruela F, Casadó V, Rodrigues RJ, Luján R, Burgueño J, Canals M, Borycz J, Rebola N, Goldberg SR, Mallol J, et al: Presynaptic control of striatal glutamatergic neurotransmission by adenosine A1-A2A receptor heteromers. J Neurosci 26: 2080-2087, 2006. 